\title{
FRIEDEBURG, Robert von, Lebenswelt und Kultur der unterständischen Schichten in der Frühen Neuzeit
}

\section{Christophe Duhamelle}

\section{OpenEdition \\ Journals}

Édition électronique

URL : http://journals.openedition.org/ifha/1113

DOI : 10.4000/ifha. 1113

ISSN : 2198-8943

Éditeur

IFRA - Institut franco-allemand (sciences historiques et sociales)

Référence électronique

Christophe Duhamelle, «FRIEDEBURG, Robert von, Lebenswelt und Kultur der unterständischen

Schichten in der Frühen Neuzeit », Revue de l'IFHA [En ligne], Date de recension, mis en ligne le 01 janvier 2003, consulté le 22 septembre 2020. URL : http://journals.openedition.org/ifha/1113 ; DOI : https:// doi.org/10.4000/ifha. 1113

Ce document a été généré automatiquement le 22 septembre 2020.

(C)IFHA 


\title{
FRIEDEBURG, Robert von, Lebenswelt und Kultur der unterständischen Schichten in der Frühen Neuzeit
}

\author{
Christophe Duhamelle
}

1 L'« Enzyklopädie deutscher Geschichte » ne cesse de s'agrandir. La « Librairie allemande » a souvent souligné l'intérêt de ces manuels qui, en moins de 150 pages, proposent une synthèse suivie d'un panorama de la recherche et d'une bibliographie abondante (442 titres pour cette livraison). Résumer ce qui concerne le Lebenswelt (qu'on pourrait maladroitement traduire par " monde vécu») et la culture des couches populaires en si peu d'espace relevait d'autant plus de la gageure qu'il s'agit là d'un des domaines les plus actifs et les plus novateurs de la recherche allemande en histoire moderne - un des plus controversés aussi, ce dont témoigne le livre de R.v.F. La seconde partie, historiographique, détaille en effet nombre de débats sur la notion de " culture populaire ». L'auteur rappelle en particulier les interrogations portant sur les relations entre "le haut " (les institutions ecclésiastiques et étatiques, la culture lettrée) et « le bas » (un « populaire » dont les limites font l'objet d'une réflexion nuancée), liens dont l'interprétation va de la pure coercition au rôle moteur de la demande communale en passant par toute la gamme possible des interactions et des influences réciproques. À juste titre, R.v.F. plaide pour une contextualisation des études sur la culture populaire, car les fructueux emprunts aux méthodes anthropologiques ne peuvent faire oublier que le monde germanique moderne manifeste déjà un haut degré d'intégration institutionnelle interdisant d'y trouver une " culture populaire " totalement autonome. Fort logiquement, l'essentiel de l'ouvrage porte donc sur l'inscription des milieux modestes dans les cadres sociaux (travail, honorabilité) davantage que sur leur exclusion, et insiste en particulier sur la confessionnalisation et la disciplinarisation sociale.

2 Tel est le choix de l'auteur ; il a sa cohérence et va de pair avec une ouverture louable envers toutes les approches (l'histoire des genres, par exemple). Il entraîne cependant quelques oublis regrettables. L'espace est ainsi conçu comme un simple cadre de la vie 
sociale : ses usages différenciés ne font pas l'objet d'une analyse. Plus surprenante est l'absence de la culture matérielle : on s'étonne, puisque les chercheurs étrangers sont souvent cités, de ne pas trouver D. Roche, ou encore de voir, en bibliographie, H. Medick (un des rares historiens allemands à avoir abordé la culture des apparences vestimentaires) figurer dans la rubrique « confessionnalisation » - on pourrait en dire autant de la fête, du mariage et de la sociabilité. Enfin, et peut-être surtout, les pratiques de la lecture, l'école et l'alphabétisation sont globalement négligées, sauf pour reprendre en quelques lignes (16 en tout, p. 20 et p. 38-39) une dichotomie confessionnelle que la recherche a depuis longtemps largement nuancée, pour dire le moins.

3 Certains manques de la bibliographie donnent une première explication à ces zones d'ombre : le nom de R. Schenda n'y apparaît pas, celui de J. Peters est sous-représenté, l'ouvrage essentiel d'A. Holzem sur le catholicisme populaire est oublié, etc. La seconde raison réside dans l'écho perceptible de querelles qu'on croyait dépassées : la possibilité de faire une " histoire du quotidien » est exécutée en 5 lignes (p. 46-47) en fonction d'arguments qui témoignent d'une grande incuriosité. La troisième explication est plus fondamentale : cet ouvrage qui se préoccupe beaucoup de délimitations conceptuelles parle en revanche très peu des méthodes et assez mal des sources; pas un mot sur l'utilisation de la méthode sérielle en histoire culturelle (certes peu pratiquée en pays germanophone, mais avec quelques exceptions, comme M. Pammer, non cité), peu de choses sur les sources judiciaires (sinon pour postuler une différence de nature entre le conflit et la vie réelle), à peu près rien sur les méthodes développées pour appréhender l'émotionnel et la perception personnelle.

4 Il est bien sûr trop facile d'énumérer les lacunes d'une synthèse historique et historiographique de 138 pages. Il est en revanche légitime d'en contester les exclusions. Mais il est nécessaire enfin de souligner la difficulté de l'entreprise et de saluer l'auteur qui a relevé le gant. 